\title{
In situ hole doping of wide-gap semiconductors by dual-target simultaneous laser ablation: GaN and SiC epitaxial films
}

\author{
Hachizo Muto, a) Takashi Asano, Rong-Ping Wang, and Takeshi Kusumori \\ Materials Research Institute for Sustainable Development, National Institute of Advanced Industrial Science \\ and Technology (AIST) Chubu, 2266-98 Anagahora, Shimoshidami, Moriyama-ku, Nagoya, \\ 463-8560 Japan
}

(Received 20 May 2005; accepted 9 September 2005; published online 14 October 2005)

\begin{abstract}
Apparatus for dual-target simultaneous laser ablation deposition and in situ doping techniques have been developed to achieve $p$-type doping during epitaxial growth of wide-band-gap semiconductors. The apparatus has two target holders with a target-rotation mechanism and a rotation-axis adjusting mechanism to obtain homogeneously doped films. Mg-doped GaN films have been fabricated on $6 \mathrm{H}-\mathrm{SiC}(0001)$ and $\mathrm{Si}(111)$ substrates in $\mathrm{NH}_{3}$ ambient by simultaneous ablation of $\mathrm{GaN}$ and $\mathrm{Mg}$-metal targets using two lasers. Junctions of the films with $n$-type substrates show a diode curve characteristic of $p-n$ junctions, but not for junction with $p$-Si, indicating hole doping without further procedures. In situ $p$-type doping to $\mathrm{SiC}$ was also achieved by using $\mathrm{SiC}$ and $\mathrm{Al}_{4} \mathrm{C}_{3}$ targets. (C) 2005 American Institute of Physics. [DOI: 10.1063/1.2105989]
\end{abstract}

As well as $\mathrm{GaN}$, both $\mathrm{SiC}$ and $\mathrm{ZnO}$ are expected to be next-generation semiconductors suitable for use in electro-optic fields, including the reduction of energy consumption. ${ }^{1-3}$ They have a wide band gap and good thermal stability originating from their very high melting or growth temperatures, respectively, $1700, \sim 2700$, and $1970^{\circ}$ C. ${ }^{4,5}$ However, the high temperatures make the device processing difficult. In particular, a breakthrough is needed for $p$-type doping along with the fabrication of high-quality crystalline layers. Dopant atoms, such as B, Al, N, P, As, Mg, and $\mathrm{Zn}$ are introduced to the films by ion implantation or by adding their metalorganic (MO) compounds during film fabrication by chemical vapor deposition (CVD) or vapor phase epitaxy. The dopant atoms cannot migrate easily. The doping process also destroys the crystalline lattice or creates unwanted complexes with hydrogen atoms produced by the decomposition of MO. As a result, charge compensation occurs, with mobile electrons associating with the lattice imperfection. For GaN, the first success in $p$-type doping was made by Akazaki using low-energy electron-beam irradiation of the doped films. ${ }^{6,7}$ The breakthrough, together with clarification of the activation mechanism, was made by Nakamura $^{8-12}$ using a sophisticated postprocedure of hightemperature annealing which made it possible to activate dopant atoms by the decomposition of Mg-hydrogen complexes after a sophisticated form of CVD called two-flow MOCVD. The $\mathrm{SiC}$ is doped by implantation of $\mathrm{B}$ or $\mathrm{Al}$ ions, or by adding their MO compounds in the CVD processing, which also need subsequent annealing at very high temperatures around $1500-1700^{\circ} \mathrm{C}^{3}$ Thus, $p$-type doping is still difficult, and alternative techniques that take only a single step at low temperatures are desirable. Using pulsed laser ablation deposition (PLAD), we have fabricated heteroepitaxial films of SiC. ${ }^{13-15}$ Polytypes, such as $2 \mathrm{H}, 4 \mathrm{H}$, and $3 \mathrm{C}-$ $\mathrm{SiC}$, were grown on sapphire and $\mathrm{Si}$ single-crystal substrates at low temperatures of $1200-1300{ }^{\circ} \mathrm{C} .{ }^{15-17}$ PLAD has many advantages and is useful for fabricating other wide gap semi-

a) Author to whom correspondence should be addressed; electronic mail: hachizo.muto@aist.go.jp conductors, such as $\mathrm{GaN},{ }^{18-21} \mathrm{ZnO},{ }^{22,23}$ and diamond, ${ }^{24,25}$ as well as superconductors, ${ }^{26}$ ferroelectrics, ${ }^{27}$ and magnetoresistance materials, ${ }^{28}$ but apparatus and techniques for doping have not been developed. Doping might be possible with conventional apparatus using a single target if mixed targets are to be prepared. However, it is hard to sinter the mixed target of a wide gap semiconductor with a very high melting temperature and a dopant that has a low evaporating temperature.

We have devised a PLAD technique for achieving in situ hole doping, as shown in Fig. 1(a). We believe that doping becomes possible if the dual targets of film and dopant are ablated separately but simultaneously, even though they have very different melting temperatures and/or chemical stabilities. PLAD also provides processing without MO. The chamber is equipped with two target holders, 1 and 2 , each of which can mount one target and has a motor-driven target rotation mechanism for homogeneous ablation and an $x-y$
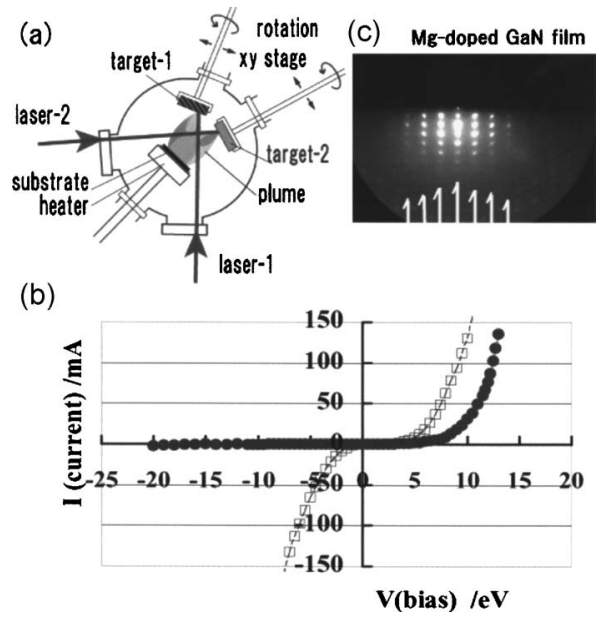

FIG. 1. Dual-target simultaneous PLAD apparatus for in situ doping during film growth using a couple of targets and lasers (a), and RHEED pattern for (i) Mg-doped GaN film (b), and $I-V$ curves observed for junctions of (i) Mg-doped and (ii) non-doped GaN films vs $n$-6H-SiC(0001) substrate (c). (a) The apparatus is equipped by two target holders with a motor-driven target rotation mechanism and an $x-y$ stage. 
stage. The substrate is mounted on a heater at the counterposition of the targets. The targets are ablated by two laser beams (1 and 2) entering the chamber through optical windows. High-energy particles are ejected from the two targets and form plumes by laser irradiation. The plume directions are adjusted using the $x-y$ stages so that both plumes just reach the center of the substrate and produce a homogeneously doped film. We used the fourth harmonic $(266 \mathrm{~nm})$ of two Nd:YAG lasers, a Spectron LS-803, and a LOTIS TII LS-2135, to ablate the film and dopant targets, respectively. The irradiation energy density (fluence: $F$ ) can be changed independently using lenses.

As targets for the films, we used sintered disks of $\mathrm{GaN}$ and $6 \mathrm{H}-\mathrm{SiC}$ with a purity of $6 \mathrm{~N}$. p-type doping was attempted using $\mathrm{Mg}$ metal as the $p$-type dopant target for $\mathrm{GaN}$, and using the four targets $\mathrm{Al}_{4} \mathrm{C}_{3}, \mathrm{~B}_{6} \mathrm{Si}, \mathrm{B}_{4} \mathrm{C}$, and $\mathrm{Al}$ metal for $\mathrm{SiC}$. Their diameter is $20 \mathrm{~mm} \phi$. The dopant concentration in the films can be controlled by changing the relative values of the PLAD parameters for the film and doping targets: The energy $E$, fluence $F$, and repetition frequency $f_{p}$ of the two lasers. It was found that the $p$-type films prepared at optimal conditions had the dopant concentration of about $2-3 \%$. The concentration was estimated from the arriving (or growth) rates of the film and dopant materials which were obtained by individual PLAD for two targets on the assumption that all arrived dopant atoms on the substrates were involved in the films even in the case of dual-target simultaneous PLAD.

Optimal conditions for Mg-doped GaN films are: $E=$ $50 \mathrm{~mJ} /$ pulse, $F=1.0 \mathrm{~J} / \mathrm{cm}^{2} /$ pulse, and $f_{p}=5 \mathrm{~Hz}$ for the $\mathrm{GaN}$ target, and $E=25 \mathrm{~mJ} /$ pulse, $F=1.0 \mathrm{~J} / \mathrm{cm}^{2} /$ pulse, and $f_{p}=$ $1 / 2 \mathrm{~Hz}$ for the $\mathrm{Mg}$ target. The doped films were fabricated on $n-6 \mathrm{H}-\mathrm{SiC}(0001)$ and $n$ or $p$-Si (111) substrates in an ammonia atmosphere at pressure $p=5 \mathrm{~Pa}$ and heater temperature $T_{h}=700-800{ }^{\circ} \mathrm{C}$. Similar conditions were used for $p$-type doping of $\mathrm{SiC}$, except for deposition in a vacuum $\left(p \sim 2 \times 10^{-7} \mathrm{~Pa}\right)$ and at a high temperature of $T_{h}$ $\sim 1200{ }^{\circ} \mathrm{C}$. The quality of the films and $p-n$ junctions was examined by x-ray diffraction (XRD), reflection high-energy electron diffraction (RHEED), atomic force microscopy (AFM), and current-voltage $(I-V)$ measurements.

XRD revealed that the Mg-doped GaN film grew with the same $c$-axis orientation as the substrate $6 \mathrm{H}-\mathrm{SiC}$. Apart from the substrate $6 \mathrm{H}-\mathrm{SiC}(0006)$ and (00012) peaks, the XRD patterns showed only two XRD peaks, at $2 \theta=34.84^{\circ}$ and $73.37^{\circ}$, which are assigned to (0002) and (0004) diffractions of hexagonal $\mathrm{GaN}$. The lattice parameter estimated from the $2 \theta$ values $(c=0.515 \mathrm{~nm})$ agreed with that of $\mathrm{GaN}$ $(c=0.517 \mathrm{~nm}){ }^{4}$ Epitaxial growth of the GaN film was confirmed by the RHEED patterns shown in Fig. 1(b), which is observed in the electron-beam direction parallel to the GaN [1-100] direction. The lattice size estimated from the line separation $(a=0.318 \pm 0.002 \mathrm{~nm})$ agrees with the reported value for $\mathrm{GaN}(a=0.3186 \mathrm{~nm}){ }^{4}$

The $I-V$ character observed for the junction of Mg-doped GaN film/(0001) $n$-6HSiC substrate is shown in Fig. 1(c) with filled circles. This displays a diode character due to the $p$ - $n$ junction, i.e., a low leak current in the reverse bias region up to $-20 \mathrm{~V}$, and a steep increase in current with the forward bias. These results clearly indicate the successful achievement of in situ p-type doping of GaN. The dead voltage at $4-5 \mathrm{~V}$ in the forward region is due to a Schottky barrier resulting from contact with a silver $(\mathrm{Ag})$ metal electrode that we used for convenience. For reference, we fabriDownloaded 13 Apr 2010 to 150.203.243.34. Redistribution subje

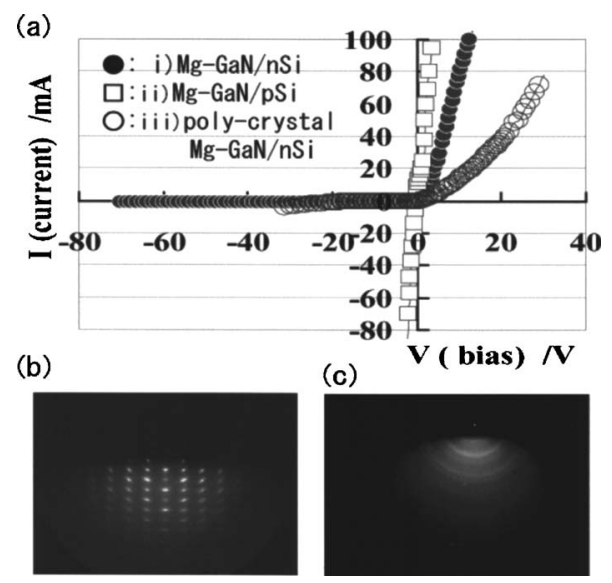

FIG. 2. $I-V$ curves and RHEED patterns for film/substrate junctions. (a) Curves are observed for the epitaxial film of $\mathrm{Mg}$-doped $\mathrm{GaN}$ fabricated on (i) $n$ - and (ii) $p$-Si(111) substrates, and for (iii) polycrystalline Mg-doped GaN film fabricated on $n$-Si(111). (b) and (c) RHEED patterns for (i) epitaxial and (iii) polycrystalline films of $\mathrm{Mg}$-doped $\mathrm{GaN}$ on $n$-Si, respectively.

cated nondoped GaN film on the $n$-6HSiC (0001) plane, which gives rise to an $n$-type film with $n$ carriers due to intrinsic lattice defects. The $I-V$ curve of the $n / n$ junction is shown by the open squares in Fig. 1(c), which displays no diode character, but does have a Schottky nature showing a symmetry with respect to reverse of the bias, except for the polarity of $I$. This is mainly due to Schottky contact between film and metal electrode.

In situ p-type doping also takes place on other substrates. Figure 2(a) shows the $I-V$ curves observed for junctions of epitaxial films of $\mathrm{Mg}$-doped $\mathrm{GaN}$ which are fabricated on: (i) $n$ and (ii) $p$-Si(111) substrates at $T_{h}=750{ }^{\circ} \mathrm{C}$ and for (iii) polycrystalline $\mathrm{Mg}$-doped film fabricated at $T_{h}=650{ }^{\circ} \mathrm{C}$ on $n-\mathrm{Si}(111)$. Their epitaxial and polycrystalline growth are verified by RHEED as shown in Figs. 2(b) and 2(c) for (i) and (iii) films. A diode character is observed for the $p$-film $/ n$-substrate junction (i) (closed circles), but a nearly straight line is seen for the $p-p$ junction (ii) (open squares). Surprisingly, a diode character was observed for junction (iii) of polycrystalline $\mathrm{Mg}$-doped film/n-Si (open circles), though the $I-V$ quality was lower than that of the epitaxial films. These results imply that the present dualtarget simultaneous PLAD causes the doping and activation of $p$-type dopant to occur readily in a single step without further processing.

The technique has also been applied to $\mathrm{SiC}$, which is very hard to dope because of its extremely high growth temperature. ${ }^{3} \mathrm{We}$ attempted in situ $p$-type doping of $\mathrm{SiC}$ using three kinds of sintered target $\left(\mathrm{Al}_{4} \mathrm{C}_{3}, \mathrm{~B}_{4} \mathrm{C}\right.$, and $\left.\mathrm{B}_{6} \mathrm{Si}\right)$ and an $\mathrm{Al}$ metal target. Success was found only with $\mathrm{Al}_{4} \mathrm{C}_{3}$. The $I-V$ curve for the junction (i) between the film and $n-6 \mathrm{HSiC}$ (0001) substrate is shown by closed circles in Fig. 3(a). A diode character is clearly observed. Other dopants result in $I-V$ curves having nearly a Schottky nature, as shown with open triangles for a typical film fabricated on $n$-SiC using $\mathrm{B}_{4} \mathrm{C}$ dopant target. For reference $n$-type-doped $\mathrm{SiC}$ film was fabricated on an $n$-SiC substrate using $\mathrm{Si}_{3} \mathrm{~N}_{4} n$-dopant target. The curve for the resulting junction is shown by the open squares. It is almost a straight line, characteristic of the $n-n$ junction. It was found that the above $p$-type film had much lower surface roughness (root-mean-square $\sim 1.0 \mathrm{~nm}$ ) than the other films $(2-5 \mathrm{~nm})$, as shown in Figs. 3(b) and 3(c), to AIP license or copyright; see http://apl.aip.org/apl/copyright.jsp 


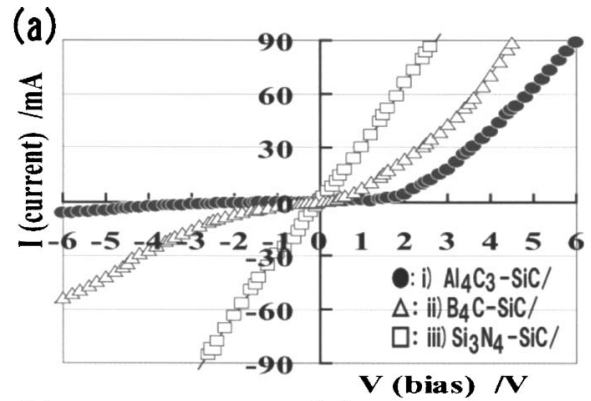

(b)

(c)

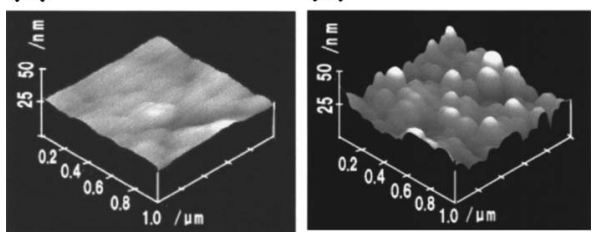

FIG. 3. $I-V$ curves observed for junctions of in situ-doped $\mathrm{SiC}$ epitaxial film $/ n$ - $6 \mathrm{HSiC}$ substrate (a), and AFM images (b) and (c) for the SiC films fabricated by dual-target simultaneous PLAD using (i) $\mathrm{Al}_{4} \mathrm{C}_{3}$ and (ii) $\mathrm{B}_{4} \mathrm{C} p$-type dopant targets. The curve (iii) in (a) shows $I-V$ character for an $n$-type film prepared using (iii) $\mathrm{Si}_{3} \mathrm{~N}_{4} n$-type dopant for reference.

while their crystallinity estimated from the full width at half maximum values of $\mathrm{SiC}(0006) \mathrm{XRD}$ rocking curves did not differ largely from each other. These results suggest that the achievement in $p$-type doping needs growth of films with high crystalline quality including surface flatness, although the detail mechanism must be clarified.

We have developed a dual-target simultaneous PLAD apparatus and corresponding techniques, and studied $p$-type doping of wide gap semiconductors, such as $\mathrm{GaN}$ and $\mathrm{SiC}$. Their successful in situ $p$-type doping on various substrates, such as $\mathrm{Si}$ and $\mathrm{SiC}$, suggests a wide applicability of these techniques to hard materials that can be grown, in addition to other wide gap semiconductors, such as $\mathrm{ZnO}$ and diamond.

${ }^{1}$ O. Madelung, Semiconductors in Group IV Elements and II-VI Compounds (1991).

${ }^{2}$ S. Nakamura and G. Fasol, The Blue Laser Diode, 1st ed. (Springer, Heidelberg, 1997).

${ }^{3}$ Silicon Carbide: A Review of Fundamental Questions and Applications to
Current Device Technology, edited by W. J. Choyke, H. Matsunami, and G. Pensl (Academic, Berlin, 1997).

${ }^{4}$ R. Juza and H. Hahn, Z. Anorg. Chem. 239, 282 (1938).

${ }^{5}$ P. B. T. Shaffer, Acta Crystallogr., Sect. B: Struct. Crystallogr. Cryst. Chem. 25, 477 (1969).

${ }^{6}$ H. Amino, M. Kito, K. Hiramatsu, and I. Akazaki, Jpn. J. Appl. Phys., Part 2 28, L2112 (1989).

${ }^{7}$ M. Inamori, H. Sakai, T. Tanaka, H. Amano, and I. Akasaki, Jpn. J. Appl. Phys., Part 1 34, 1190 (1995)

${ }^{8}$ S. Nakamura, T. Mukai, M. Senoh, and N. Iwasa, Jpn. J. Appl. Phys., Part 2 31, L139 (1992).

${ }^{9}$ S. Nakamura, N. Iwasa, M. Senoh, and T. Mukai, Jpn. J. Appl. Phys., Part 1 31, 1258 (1992).

${ }^{10}$ S. Nakamura, Science 281, 956 (1998).

${ }^{11}$ Y. Kamiura, Y. Yamashita, and S. Nakamura, Physica B 273, 54 (1999).

${ }^{12}$ S. Nakamura, N. Iwasa, M. Senoh, and T. Mukai, Appl. Phys. Lett. 64, 1687 (1994).

${ }^{13}$ H. Muto and T. Kusumori, Mater. Sci. Forum 389, 371 (2002).

${ }^{14}$ H. Muto, T. Asano, and T. Kusumori, Mater. Sci. Forum 433, 255 (2003).

${ }^{15}$ H. Muto, S. Kamiya, and T. Kusumori, Opt. Mater. (Amsterdam, Neth.) 23, 43 (2003)

${ }^{16}$ T. Kusumori, H. Muto, and M. Brito, Appl. Phys. Lett. 84, 1272 (2003).

${ }^{17}$ G. Chin, Science 303, 1731 (2004).

${ }^{18}$ D. H. Lowndes, D. B. Geohegan, A. A. Puretzky, P. D. Norton, and C. M. Roleau, Science 273, 898 (1996).

${ }^{19}$ R. D. Vispute, V. Talyansky, R. P. Sharma, S. Choopun, M. Downes, K. A. Jones, A. A. Lliadis, M. A. Khan, and J. W. Yang, Appl. Phys. Lett. 71, 102 (1997)

${ }^{20}$ R. P. Wang, H. Muto, Y. Yamada, and T. Kusumori, Thin Solid Films 411, 69 (2002).

${ }^{21}$ X. W. Sun, R. F. Xia, and H. S. Kwok, J. Appl. Phys. 84, 5776 (1998).

${ }^{22}$ A. Tsukazaki, A. Ohtomo, T. Onuma, M. Ohtani, T. Makino, M. Sumiya, K. Ohtani, S. F. Chichibu, S. Fuke, Y. Segawa, H. Ohno, H. Koinuma, and M Kawasaki, Nat. Mater. 4, 42 (2005).

${ }^{23}$ T. Nakamura, Y. Yamada, T. Kusumori, H. Minoura, and H. Muto, Thin Solid Films 411, 6064 (2002).

${ }^{24}$ M. Yoshimoto, K. Yoshida, H. Maruta, Y. Hishitani, H. Koinuma, S. Nishino, M. Kakihana, and T. Tachibana, Nature (London) 399, 340 (1999).

${ }^{25}$ F. Qin, V. Craciun, R. K. Singh, S. D. Dutta, and P. P. Pronko, J. Appl. Phys. 86, 2281 (1999).

${ }^{26}$ D. P. Norton, A. Goyal, J. D. Budai, D. K. Christen, D. M. Kroeger, E. D. Specht, Q. He, B. Saffian, M. Paranthaman, C. E. Klabunde, D. F. Lee, B. C. Sales, and F. A. List, Science 274, 755 (1996).

${ }^{27}$ H. N. Lee, D. Hesse, N. Zakharov, and U. Gosele, Science 296, 2006 (2002).

${ }^{28}$ S. Jin, T. H. Tiefel, M. McCormack, R. A. Fastnacht, R. Ramesh, and L. H. Chen, Science 264, 413 (1994). 